\title{
Kant on Remote Working: a Moral Defence
}

\author{
Fausto Corvino ${ }^{1}$ (D)
}

Received: 3 June 2021 / Accepted: 5 October 2021 /Published online: 20 November 2021

(c) The Author(s), under exclusive licence to Springer Nature Switzerland AG 2021

\begin{abstract}
In this article I maintain that when employers could free workers from the space constraint of the office without incurring unbearable economic losses, it is morally wrong not to grant workers the possibility to work remotely, as this violates the humanity formulation of Kant's categorical imperative. The article therefore aims to contribute to the development of Kantian business ethics, taking into account a series of empirical evidence gathered in the wake of the Covid-19 pandemic. I firstly discuss the Kantian concept of meaningful work and explain why, due to a prejudice that existed with respect to remote work before the Covid-19 pandemic, the issue of freedom from the office was not given normative relevance. I then introduce a Kantian argument in defence of remote work and proceed to discuss two objections. The first objection is that remote work may well foster productivity, but it creates problems in terms of innovation and training of new staff. The second objection is that remote work hinders rather than fosters meaningful work because it deprives employees of social relations and inhibits workplace identity. I conclude by explaining why neither objection undermines the normative argument that workers should be allowed to work remotely as long as the "bearable costs" clause is met.
\end{abstract}

Keywords Norman Bowie · Categorical imperative · Kant · Remote work · Covid-19 . Meaningful work

\section{Introduction}

Kantian-inspired business ethics has so far not given due weight to the role played by employers' demand for the physical presence of workers in a given place, usually the office, with respect to the duty to treat the parties to the employment contract as ends and not as means. The Kantian interpretation of the notion of meaningful work, proposed a few years ago by Norman Bowie $(1999,2017)$ - and discussed at length in the literature (see Ciulla 2012; DesJardins 2012) - focuses on all those things that the company can do inside the office to make work less alienating and more in line with the human development of the workers, but scarcely questions the coercive aspect of the office, understood as a place

Fausto Corvino

f.corvino@santannapisa.it

1 Sant'Anna School of Advanced Studies, DIRPOLIS Institute (Law, Politics and Development), Piazza Martiri della Libertà, 33, 56127 Pisa, Italy 
where the physical presence of the worker is required from a certain time to another, or for a minimum number of hours per day.

The premise in this article is that this is due to a bias against remote working that existed before the Covid-19 pandemic: the economic benefits of remote work were considered inferior to the loss of productivity it would induce, and it was also thought that remote working would cause more problems than benefits for workers (e.g., isolation, loneliness, boredom, etc.). The second premise is that the Covid-19 pandemic has demonstrated the inaccuracy of this bias. Most workers in the world consider themselves equally or more productive at home than in the office, and a substantial number of workers say they would like to continue working remotely at least a few days a week. These two premises therefore lead me to put forward the following normative argument: in all cases where there is no empirical evidence that remote work causes unbearable profit losses for the company, it is morally wrong not to offer workers the possibility of working remotely. This is because remote work can allow for greater alignment between contractual obligations and freely chosen personal goals. To deny employees this possibility is tantamount to violating the humanity formulation of the categorical imperative, and is therefore morally wrong, at least from a Kantian point of view.

In section I, I present the notion of meaningful work and I explain why it is relevant with respect to remote work. In section II, I present my main normative argument and I outline what I define as the "bearable costs" clause. In section III and IV, I address two objections to the empirical and normative arguments of the article: remote work may well foster productivity, but it is a clear obstacle to innovation and training, and this could cause economic losses to the company which would take remote work outside the "bearable costs" clause (III); remote work hinders rather than fosters meaningful work because it deprives workers of social relations and curbs workplace identity (IV). I therefore wrap up my reasoning in the conclusions.

\section{I - Meaningful Work and Remote Work}

In the humanity formulation of the categorical imperative (HF) Kant $(1785,4: 428)$ maintains that we should never treat humanity, neither in ourselves nor in others, as a means but always as an end in itself. This moral principle can be interpreted both in a negative and in a positive sense. In the negative sense, it means that we must not place obstacles in the way of others in the development of their rational capacities, provided, of course, that any restrictions are not necessary to guarantee the freedoms of yet others. So, for example, it is morally wrong, according to HF, to force a person to make a gin and tonic, but there is nothing wrong with going into a bar, ordering a gin and tonic, and paying what is on the menu - as this complies with transaction rules to which the bartender has rationally adhered. In the positive sense, instead, the HF means that we should take positive actions to enable people to pursue their personal development goals freely. This second type of duty is, unlike the first, imperfect, in the sense that it does not translate into precise prescriptions and it leaves ample room for discretion as to whether and how to fulfill it. In the case of the bartender, therefore, we could say that there is both a positive imperfect duty, on the part of the bartender herself/himself, to develop her/his rational capacities to the fullest, and also an imperfect duty attributable to the individuals with whom the bartender interacts to put her/him in the best possible conditions to flourish as a human being - and this can be done, for example, through dialogue (and in particular by encouraging her/him 
and recognising the proper value of her/his achievements), by making training and learning opportunities accessible to her/him, by providing her/him with the adequate economic resources and free time to pursue freely chosen life goals, and so on (see also Hill 1980; Nelson 2008; Formosa 2014).

The HF has triggered a very intense debate on whether and how this moral principle is compatible with the wage bond. After all, the wage contract looks exactly like a social object designed to treat other people as means: whoever has capital hires a worker, assigns her/him tasks which are not necessarily compatible with her/his individual objectives, and which aim at the goal of profit, and thus ultimately at the accumulation of capital (see also Hill 1980, 89-90). The first comprehensive treatment of this issue was made by Norman Bowie (1999, 2017), in his illuminating Business Ethics: A Kantian Perspective. With respect to the negative aspect of HF, Bowie addresses two main questions: whether the job contract is coercive in itself and whether the cancellation or non-renewal of the contract by the employer is coercive with respect to the employee. Bowie responds positively to the first question, he maintains that from a Kantian perspective a person is not free to enter a job contract in so far as she/he has no access to some market-independent income (Bowie $2017,51)$. Conversely, Bowie $(2017,53)$ maintains that laying people off is not coercive if the company has no reasonable alternative to it. In general, Bowie (2017, 53-59) adds, the more workers are asked for their consent, either through direct participation, e.g., open book management, or through hypothetical consent, i.e., by taking decisions that workers cannot reasonably reject, the less coercive the company's decisions will be.

The most interesting and original part of Bowie's Kantian interpretation of business ethics concerns, however, the positive component of HF. According to Bowie (2017, 66-78), companies do not simply have the perfect moral duty not to coerce workers, neither towards nor within the job contract; they also have the imperfect moral duty (i.e., a duty of beneficence) to offer workers "meaningful work". The difference between the two types of duty lies in the fact that the first, negative, duty, is a perfect duty: it indicates a precise action which it is right to perform and wrong not to perform (or the opposite), regardless of its consequences. The second, positive, duty, on the other hand, is an imperfect duty: it indicates a course of action or a type of action that is ethically right to perform, but not always obligatory. The boundaries of the duty of beneficence and especially the extent to which the individual must sacrifice her/his own well-being in order to promote the happiness of others are not clear in Kant's philosophy and have always been the subject of theoretical dispute (O’Neill 2000, Herman 2010, Hope 2014).

By meaningful work, Bowie means two main things. First, a job that is remunerated adequately to allow the worker to be sufficiently well off and hence also to satisfy some desires that are independent from work (basically, all the things people pay for through their salaries). Second, a job that does not interfere with workers' autonomy and rationality, and that facilitates workers in their human development. I will not comment more on the salary condition, because I think it is self-evident. What interest me the most here is the second condition of meaningful work, that we may call the human-development condition, because both autonomy and rationality are pre-conditions for the subsequent objective of human development, or also human flourishing (see Hill 2002: 164-200).

I take human development to be, at least in a Kantian sense of the expression, a process through which the individual uses practical reason for setting long-term life goals, and then employs her/his intellectual capacities to pursue these goals, in a process of continuous individual improvement (see also Hill 1998). In this sense, human development is also moral development, which in the end is supposed to culminate, at least according to Kant's teleological view, in a moral community (see also Kant 1795; Kleingeld 1999). 
When we reason about what it means to enable a worker to pursue human development, we can refer to two things, as Bowie $(2017,70-73)$ also does. One concerns the exercise of job functions. The more the functions are misaligned with the life goals the worker has set for herself/himself, the more the job becomes hostile to the pursuit of human development. In general, repetitive tasks and/or tasks that have no intrinsic meaning of their own are the ones that are most unlikely to foster human development. On the contrary, a job that allows the employee to put to work and to refine what she/he has learned during a freely chosen course of study certainly contributes to human development, at least in the Kantian sense of the expression. Secondly, a job that hinders the human development of the worker is one in which the worker is allowed to use her/his rational capacities to pursue non-instrumental goals, but yet these goals are imposed from above by the company on the workers, rather than being freely chosen (e.g., nudging and codes of ethics on which workers have not had the opportunity to express themselves). ${ }^{1}$

Returning to the bar case, it is possible to understand the difference between the perfect duties of the employer, on the one hand, and the imperfect duty to offer meaningful work, again on the part of the employer, on the other hand. Under no circumstances may an employer coerce (or push by deception) another person into making a gin and tonic, regardless of the advantages that may accrue to herself/himself, to the community or even to the bartender herself/himself. In addition to this there is also an imperfect duty, on the part of the employer as well, to ensure that the person who makes gin and tonics in the bar (for a fair remuneration and through a free agreement) can align the work activity with her/his personal development plans. The boundaries of this second duty, however, remain undefined. More specifically, it cannot be definitively and universally established whether and what costs should be imposed on the employer to maximise the alignment of the employee's work and life goals. We could thus say that meaningful work is an ethically sound thing to offer, from a Kantian perspective on business ethics, because it allows the employer to treat the employee more as an end rather than a means (as HF requires); yet, there are some circumstances in which the employer is not obliged to provide meaningful work - e.g., when by adapting work tasks to workers' aspirations, the employer jeopardises the same company.

Accordingly, one valid way to approach the employer's duty to provide meaningful work is through the "bearable costs" clause: the employer has the obligation to make work more meaningful for the employee, where the technical conditions exist for this to happen and as long as the implementation of this moral duty does not determine an excessive disadvantage for the company in relation to its competitors and/or an unsustainable loss of profit (see also Schwartz 1982, 639-644). In other words, it would not make sense to argue that a company producing wine, for example, has a moral duty to ensure that no worker has to pick grapes. Or that a car manufacturing company has a moral duty to assign

\footnotetext{
${ }^{1}$ I consider nudging by the entrepreneur as contrary to meaningful work in those cases where the life goals of the employee are different from those that the employer, however in good faith, tries to get the employee to adopt. Imagine an employer who nudges workers into having retirement plans. As long as the employee is sincerely convinced of the importance of saving now in order to have more money tomorrow, but fails to implement this good intention (e.g., because she/he is stuck in a procrastination loop), then the employer's nudging can be understood as being in line with the employee's goals. But if, on the other hand, the worker is determined to spend her/his money now, heedless of what will happen in the future, any nudging (however gentle) in the opposite direction is a form of paternalistic interference that is incompatible with meaningful work (see also Hill 1980: 97). I am grateful to an anonymous reviewer for prompting me to clarify this.
} 
intellectually stimulating jobs to all employees, fully automating the assembly lines and moving the entire workforce to offices and assigning them tasks that are more in line with their personal goals. In the case of grapes, I think it is still technically impossible to entrust the grape harvest to robots; in the case of cars, on the other hand, full automation of production processes is perhaps possible, but would require very expensive investments, and above all it is unthinkable that after full automation the company could avoid reducing the workforce, and instead even assign them meaningful work.

The "bearable costs" clause acquires a central role not only for the job tasks, but also for the location of work. When Bowie formulated his Kantian theory of business ethics, he never explicitly dealt with the location issue. He took for granted that, in general, for a person to work for a company, she/he has to spend her/his day, or part of it, in the place where the company is physically located, or in the place (or also travelling to the place) that the company assigns to her/him. Thus, the location is somehow beyond the scope of meaningful work. It could happen, as it usually happens, that a company obliges you to spend your day far from home, perhaps also in a geographical place, or in a part of the city, which is not particularly pleasant, and which you would not frequent if you were not obliged to for work. In many other cases, it may happen that you live in a certain city, and the company that wants to hire you is located in another city, and then you either have to move, with your family, to the city of the company, or you have to accept to move alone and live most of the time away from your loved ones. Both forms of coercion (both commuting and relocation) are not treated by Bowie as impeding meaningful work, since they were conceived - rightly so until recently - as being inextricable from the employment contract. Of course, one can ask a company to make the workplace less alienating and more pleasant, or to make working hours more flexible, but it would be absurd to ask the company to eliminate the very concept of the workplace.

The argument I want to defend in this article is that this second demand is no longer so absurd. As The Economist (2021: 6) recently noted: "a popular cliché of 2020 was that covid19 accelerated preexisting trends. Yet that is a poor description of the massive rupture to office work. Before the pandemic Americans spent $5 \%$ of their working time at home. By spring 2020 the figure was $60 \%$. The shift has gone better than expected". The Covid-19 pandemic forced billions of people to adapt to working remotely, familiarising themselves with software such as Zoom, Webex, Google meets, which were already present before the virus, but which were decidedly underused, i.e., they were conceived as a remedy in all those cases where physical contact was not possible. Conferences, university lectures, medical examinations, consultations, banking, research activities, and so on, were all conceived and preferred live, wherever possible.

With the Covid-19 pandemic, many workers realised that they could perform the same functions as they did in the office from home, without experiencing significant drops in productivity, indeed in many cases even increasing productivity. This, in my view, brings remote working within the "bearable costs" clause for many jobs and thus makes access to remote work a necessary condition for meaningful work.

\section{II - Remote Work and Morality}

Even before the Covid-19 pandemic, we had technologies available that could reasonably replace traditional face-to-face meetings. We simply didn't exploit them, I think, because of an underlying prejudice. We knew that these technologies would be much cheaper than 
traditional meetings, but we believed that the loss in effectiveness would be so great as to outweigh the cost savings. The Covid-19 pandemic showed us that this prejudice was misplaced. Billions of people around the world have been left at home by companies, without the possibility of preparing their teams for this new mode, and the results have been positive, both for workers and employers. According to a PwC's US Remote Work Survey (2021), the $83 \%$ of American employees think that the remote-work experiment has been successful (an increase of $10 \%$ compared to workers who shared this view in mid2020). According to Flexjobs (2020), who surveyed more than 4.000 remote workers in USA, $95 \%$ of workers said that they have been equally or more productive from home than they were in the office (and the $51 \%$ of respondents even think that productivity increased). Moreover, $65 \%$ of workers said that they would like to remain at home, while the $31 \%$ said they would prefer a hybrid contract (some days at home, some days in the office). And the $27 \%$ of workers are also willing to accept a wage reduction (between $10 \%$ and 20\%) to get recognized the status of remote worker also after the Covid-19 pandemic will be over.

Similar data appear in Europe. According to Eurofond (2021), 31), almost half of the European workers spent periods working remotely in 2020. Moreover, $77 \%$ of European workers declared to be satisfied with their remote work and the $78 \%$ said that they would like to work from home, at least some days per week, also independently of Covid19 restrictions (Eurofond 2021, 34). And it is also interesting to note that, according to the Eurofond survey $(2020,34)$, the positive attitude towards the possibility of working remotely even after the pandemic is significantly higher in those who actually experienced this way of working during lockdowns. If we combine this evidence with the data for the United States recorded by PwC (2021), and cited before, according to which the approval rating for remote working rose by ten percentage points in 2021 compared to 2020, then it is quite clear, in my opinion, that there was a bias against the advantages of remote working, and that the pandemic has forced most people to revise their judgements in this regard.

There is no space here for discussing all the potential benefits that remote work could create and to weight them against costs, either psychological, social or economic. I would therefore simply distinguish between the effects that the technological-induced possibility of separating in space the worker from the work performance usually has on companies and workers - and I leave aside here the benefits that remote work could have on society, e.g., less crowded and polluted big cities, and a demographic and economic redistribution from the centre to the suburbs and small towns. ${ }^{2}$ As for companies, the advantages of remote working are less need for space and for expensive buildings. Actually, many companies are reconsidering their real-estate portfolio in the post-pandemic, and foresee the possibility of reducing the availability of office space for workers (McKinsey 2020). This, in turn, would also lower the variable costs of energy, cleaning, air conditioning and so on. Moreover, it has been maintained that remote work could help companies attracting and retaining talents, and it also allows them to put people in contact much more easily and to obtain very short-term services and consultancy from young experts (Adecco 2021). To this, we should also add the increase in labour productivity that many employers and employees registered.

\footnotetext{
${ }^{2}$ Whether and how this impacts positively or negatively on climate change is a question to be answered on a case-by-case basis. On the one hand, we could assume that decongesting cities and reducing the number of commuters will reduce GHG emissions. On the other, one could argue, as an anonymous reviewer does, that moving people to smaller towns or to the suburbs makes car use more frequent. Personally, I believe that working remotely brings net climate benefits in most cases, but the issue is complex and cannot be addressed here.
} 
As for the problem that remote work raises for companies, we should mention difficulties in coming up with innovations, a more difficult path to train new staff, and a greater organisational and evaluation effort on the part of managers (Microsoft 2021). The latter must be able to coordinate and make a team produce without keeping it under control in a common space, and they must also change the method of evaluating the work of employees, which must no longer be based (exclusively) on the number of hours worked (which with remote working become more difficult to control) but on the productivity of the individual worker, measured on a daily basis or even over a longer period of time. It is also important to mention the data security costs that working remotely creates for companies, as all information exchanges that used to take place exclusively in the offices now pass through the web (Whitney 2021).

With respect to workers, the discourse would probably be much longer. One key advantage is greater freedom to organise one's day, the possibility of spending more time with one's family (if one likes), the elimination of time lost travelling to and from work (which for some people can take hours) and therefore of the costs involved, the possibility of living a healthier life (using, for example, the hours saved on commuting for physical activity, or whatever makes the worker feel good), the possibility of performing work in the place the worker prefers. Among the problems that remote work can cause to the worker are the sense of isolation (accentuated in cases where the worker lives alone), the loss of social dynamics related to work (both during and after working hours), the loss of autonomy from one's own family (which is amplified in all those cases where the worker has something to hide from the people who live with her/him), and lastly the lack of equipment and inferior working space compared to that in the office (see Duell 2021).

It is not in my interest here to engage in an empirical discussion of how many are the jobs in which the advantages of remote work outweigh the disadvantages for firms and/or workers. Instead, I want to develop a moral argument from two well-established empirical data from the Covid-19 pandemic:

1) there are specific jobs that companies can have their employees do remotely without unbearable economic loss for them (weighing up parameters such as productivity of the individual worker, capacity for innovation, fixed and variable costs associated with managing office space). Unbearable costs are those that could undermine the company's competitiveness or make it lose market share.

2) there are at least some workers who derive greater well-being from doing their work remotely than in an office.

3) when the conditions set out in points 1 and 2 are met, depriving workers of the capability for remote working is an unjustified unfulfillment of the imperfect duty to provide meaningful work, and it is immoral from a Kantian perspective on business ethics.

Having the possibility of deciding where to spend the longest and most challenging part of one's life (both in a broad geographical sense and as a location within a restricted geographical space) is a decisive condition, certainly among the most decisive, for the pursuit of rationally chosen life goals and for moral development. Unless the company demonstrates, unequivocally, that remote working endangers its very financial viability - for example because it generates an advantage for its competitors that risks pushing it out of the market or because it does not allow it to obtain a profit rate necessary to sustain the investments required in the sector - there are no ethical arguments, on the part of the employer and/or of the shareholders, that can reasonably oppose remote working and the 
importance it has for individual rationality. ${ }^{3}$ In Bowie's own terms, "work that unnecessarily deadens autonomy or undermines rationality is immoral" (Bowie 2017, 70).

An objection to my argument might be that since the duty to offer meaningful work is imperfect, it is not possible to define sharply its priority with respect to other duties, or even simply with respect to the employer's expectation of obtaining the highest possible profit. My answer is that being able to decide where to live and where and with whom to spend one's time, both working and free, is one of the essential conditions for human development, as is having access to a minimum income. Until the technologies necessary to work remotely existed, and until the Covid-19 pandemic forced us, in spite of ourselves, to realise the potential of these technologies, the employment contract was an implicit compromise for those without access to alternative forms of income: a wage in exchange for giving up a crucial part of their self-development goals. Nobody, of course, contested this because it went beyond the "bearable costs" clause. The company needed the worker in the office or on the shop floor to make a profit, and without profit there would be no wage. Now we know, instead, that in many cases it is possible to make a profit without forcing the worker to living in a certain city or sharing the living space for many hours a day with people she/he did not choose. The epoch-making transformation that remote working could have in the long history of capitalist evolution, and which would make it possible to treat workers as ends in themselves, not only with respect to the wages they receive and the tasks they perform in the company, but also with respect to their broader life and social projects outside work, must necessarily take ethical precedence over the reasons to maximise financial returns. ${ }^{4}$

An important thing to specify with respect to point 3 is that it should be understood in terms of capability and not functioning. When the company can afford it (because the balance of costs and benefits is positive or not so negative as to entail unbearable disadvantages) (1), the worker must be granted the capability to work remotely (3); whether the worker then decides to realise this capability or not, will obviously depend on personal considerations (2) and it does not impinge on the normative argument (3). In other words, I do not mean that the condition in point 2 applies to everyone; but for those to whom it does apply, the company has an imperfect moral duty to offer what is specified in point 3 . The second thing that I want to stress pertains to point 3, i.e., to the argument that remote work could lead, at least for some workers, to an increase in the meaningfulness of work. I already listed many benefits that remote work could bring to workers, but I still need to clarify why these benefits are desirable in a Kantian sense, rather than for mere consequentialist reasons.

The workplace is where, on average, people spend a considerable part of their lives, and it is also where they spend the unfree part of their time, i.e., where they are subject to wage-contract restraints (see Gini 1998). Enabling people to spend this time in a place that is not only a source of wellbeing, but which is in line with the worker's human development goals, is a way of making her/his work more meaningful. A distinction must be made here between hybrid forms and radical forms of remote working. The hybrid form, which many companies are turning to in the post-pandemic period, involves the worker spending part of the week in the office and part at home, while radical forms of remote

\footnotetext{
3 Obviously, where companies operate as monopolists or benefit from market imperfections, the margin of "loss" they can afford to free workers from the constraints of the office is much higher.

4 I am extremely grateful to an anonymous reviewer for pushing me and also helping to clarify this fundamental point.
} 
working involve the worker being permanently detached from the office (Capgemini 2020). The contribution that hybrid forms of remote working can make in terms of meaningful work is objectively more limited. The worker simply gains more organisational autonomy on her/his "days off", can better combine her/his work goals with her/his attachments and can contribute more effectively to domestic care work.

The radical version of remote working, on the other hand, allows the worker to break the spatial constraint of residence in the vicinity of the workplace, and thus to pursue her/his true life-goals without having to give up wage income and career opportunities. A worker in a hybrid scheme working for a London company will continue to hang out with people in London, have children who will go to school in London, take part in London political life, and so on. Working for a company in London will make many of these choices inevitable, regardless of whether they are in line with the employee's life goals. Conversely, a permanent remote worker may decide to work for a company in New York while living and pursuing her/ his social relationships in a small village on the coast of Portugal, and if she/ he gets tired, after a few years she/he can move to Morocco, or any other country. In other words, the permanent remote worker limits, indeed almost neutralises, the interference of work in the development of her/his social life (see also Kelly 2020). And this is certainly in line with the humanity formulation of the categorical imperative (HF), from which Bowie's notion of meaningful work is drawn. Through work, the individual puts into practice and refines her/his talents and skills. Through the geographical separation between the physical place of the worker and the place to which the work performance flows, the worker avoids that the employment contract determines her/his life path from the outside, instead of choosing it freely.

\section{III - The Innovation Objection}

While the majority of employers and employees recognize that remote work has not determined losses in individual productivity, there is widespread fear that remote work will hinder innovation. The thought is that it is possible to keep employees working from home on an established project, for example, but it is much more difficult for people who never met in person to come up with an original idea for a new project. If and when this proves to be true, condition 1 does not apply and therefore duty 3 does not hold. Think for example of a company that bases its profitability mainly on the rate of innovation and would no longer be able to design good products after having redeployed its workers remotely - either because the company has tried this modality of interaction, perhaps during the Covid-19 pandemic, and it has experienced the drop in innovation, or because the company has good reason to expect it to happen. It would not make sense for a worker to invoke duty 3 with respect to this company.

There are three main reasons that can explain the fear of loss of innovation. The first is that video calls prevent a full human exchange between workers, because body movements, hand movements, and the way facial expressions change in relation to posture and body movements are less noticeable (Samuels 2020). Workers become mere faces, with which it is difficult to associate tastes, quirks and gestures. This significantly reduces empathy between workers and hinders the free flow of ideas and feelings. The second reason is that remote work reduces the time of interaction between workers, as breaks, jokes, lunches, coffee breaks are missing (see Hickman 2019). Thus, it might be thought that the less workers interact, the less likely they are to come up with something good and new. Third, 
remote work does not favour extra-work meetings between colleagues, both because there is no office and there can be no after-office drink or walk or shopping, and because people who only meet on video lack the confidence needed to organise events such as dinners, cinema, theatre, family get-togethers, and so on (Morgan 2020). So the fear is that the less time workers interact and the less intimate they are, the less prolific the team will be in devising new projects, new products, new models or new business solutions.

It is obviously impossible in the space of this article to fully address the empirical aspects of the innovation objection, hence I will limit myself to doing two things: firstly, I will argue that the objection is less extensive than it appears, and then I will explain why a loss of innovativeness due to remote working, and not counterbalanced by other advantages for the company (e.g. an increase in productivity), does not automatically falsify condition 1 of my normative argument. The fact that many people experience a gap between remote work and ability to innovate does not mean that the gap is (at least at the moment) unbridgeable from a technical point of view. Remote-work technologies allow modes of interaction that are at least theoretically comparable to the real ones. Think not only of video apps, but also of cloud software and project-management tools. Obviously human contact is less in virtual exchanges than in real ones - it suffices considering that in online meetings bodies are absent, or rather hidden. However, if we think about the exchange of information, from verbal to written communication, technologies are complete substitutes for live exchanges, or almost. And in some cases, they even offer advantages, compared to live exchanges, such as the ability to interact on sophisticated document-sharing operating systems at different moments (and therefore more compatibly with private life dynamics) and the possibility to organise short, targeted meetings at any time. This is just to say that the innovation objection cannot be generalised to all types of work. If a team of people is used to writing scripts for TV series through a constant exchange that continuously intersects work and private life, it is very likely that working remotely would bring a loss of innovativeness that would be difficult, if not impossible, for the employer to accept. But if a group of mathematicians is carrying out a research project in advanced stochastic analysis, it is much more likely that targeted meetings via video calls and a sophisticated cloudstorage software could offer a good degree of substitutability compared to the office.

Here the "bearable costs" clause to meaningful work returns central. I am not holding that all jobs, if put remotely, will pass the innovation objection. Nor am I necessarily denying that the great majority of jobs might suffer a loss of innovativeness if put online - I believe the opposite, i.e., that some jobs might even become more innovative if done remotely, but for now I accept the more restrictive position. I only maintain that when the analysis of the advantages (lower fixed and variable costs and possibly higher productivity or even only stable productivity) and disadvantages (lower possibilities of innovation for the team) of working remotely does not result in an unsustainably negative balance, denying the employee the possibility of breaking the tie that binds her/his to the office is immoral. Any argument in favour of profit maximisation for the employer is ethically inferior to the duty to treat employees as ends in themselves as regards the place of their existence.

There is also a final aspect, combining empiricism and normativity, which is worth highlighting concerning the innovation objection. A worker who agrees to work remotely does so because she/he believes she/he can derive a benefit from it. And the utility that a person gets from not being in a certain place may come either from the fact that she/he is not comfortable there or from the possibility that there is another place where she/he would most like to be. In both cases, the realized capability for remote work is expected to increase individual wellbeing, and it is a matter of facts that subjective wellbeing impacts 
positively on individual creativity (Engelbrecht 2014). Hence, it might be the case that a loss in group innovativeness could be compensated by marginals increases in individual creativity unleashed by breaking the employee-office bond. After all, as an anonymous reviewer rightly pointed out, the same Kant did most of his work remotely.

Moreover, being free from the office means being potentially free to perform the job tasks from wherever the employee wishes. On average, we could foresee that a remote worker will spend more time working in different locations than the office employee does - and I am referring not simply to change of city, almost as if I were proposing a fictional version of the nomadic worker, but also more simply to momentary changes of location, just think of the change from indoors to outdoors. In this sense, there may be cases, especially those related to creative or problem-solving work, where freedom of movement, and thus also greater autonomy in organising one's working day, may expose the worker to more intense exchanges with the social context around her/him, and ultimately this may prove to be a source of greater inspiration than the office.

\section{IV - The Isolation Objection}

There is, however, a second possible objection to my normative argument: working remotely makes work less meaningful, rather than the opposite, because it isolates the worker from the group. Isolation from colleagues can raise three different problems to the employee: a) it prevents those extra and intra-work exchanges that make work more enjoyable; b) it makes work more alienated because it becomes more difficult for the remote worker to feel part of a collective productive effort; c) it makes it difficult, if not impossible, to show both relational and physical "identity markers" (see Elsbach 2004). I consider all three of these points empirically valid: for many workers, remote working has represented a loss of well-being, and many during the Covid-19 pandemic were itching to return to their former office life. From this, however, it cannot automatically be deduced that remote working is not meaningful. On the contrary, I think these cases only show that office life has become so pervasive and conditioning for many workers that they have found it difficult to find meaningful alternatives in their private lives. Far from showing that remote working is a problem, this is a symptom of a social pathology: the social sphere of work partially or completely annihilates the private sphere, and therefore the individual cannot do without work to carry out those human exchanges that have nothing to do with the employment contract. Accordingly, if meaningful work is the objective, i.e. a job that allows the individual to realise freely chosen objectives, the return to the office is not the cure, but an insistence on the illness.

Honestly, it could be observed that the isolation argument is not admissible when based on empirical evidence gathered during the Covid-19 pandemic, in which everyone's private life was restricted due to movement bans: we should not be surprised, in short, if people have struggled to find viable substitutes for office social life in the midst of national lockdowns. Thus, the isolation objection could simply be put aside. Yet, I believe that much of the malaise that some workers experienced while working from home during the Covid-19 pandemic would have been experienced also in normal circumstances, thus I consider it worthwhile to address the three specifications of the isolation objection.

Point (a) is quite evident, so it does not require much introduction. When working from home we only keep the serious part of the job, and lose all the more pleasant aspects, 
resulting from human exchanges with colleagues. My response is simple: colleagues are arbitrarily imposed on the worker; remote working, instead, allows the worker to choose the people with whom she/he wants to have exchanges. This can be done in two ways, either by sharing the workspace with chosen people (relatives, friends, acquaintances), or by working alone and using the free moments (either during or before or after the work performance) to have exchanges with the people one wants. Obviously, it takes time for the increased freedom of remote working to translate into increased well-being. When discussing a possible future in which economic growth and technological progress would relieve a substantial part of the population from the need to work, John Maynard Kenyes (2008: 22) wrote that "if the economic problem is solved, mankind will be deprived of its traditional purpose". He looked very positively at what he described as the "the greatest change which has ever occurred in the material environment of life for human beings in the aggregate", but he also recognized that "it will all happen gradually, not as a catastrophe" (Keynes 2008: 25). Before this collective change generated widespread positive effects, it was possible, according to Keynes (2008: 22), that some people would have had "a nervous breakdown". Quite similarly, Bertrand Russell (2004: 1-15), when debating the possibility of reducing the duration of individual work as a result of technological advances and of a better organisation of production, maintained that in the modern world, in which the "capacity for light-heartedness and play [...] has been to some extent inhibited by the cult of efficiency", "men would not know how to fill their days if they had only four hours of work out of the twenty-four".

I believe that something similar should be argued in response to point (a). The end of office as a necessary and generalized duty, would for many cause depression, anxiety, loneliness, loss of individual purpose, and so forth. But we should accept the fact that the move towards a collective organisation of work that is more meaningful involves a momentary loss of individual well-being for some, just as a course of de-addiction involves a high level of initial suffering. And just as in the case of de-addiction, individual suffering is made necessary by the transition from a sub-optimal state induced by the intake of the addictive substance to an optimal state, so in the case of the transition towards remote working, the sense of disorientation derives from the fact that for too long the employment contract has encroached excessively on the individual life of the worker, conditioning both the place where the working day is spent and the way in which it is spent, and this has resulted in the office becoming for many the main, if not the only, source of meaning and human exchange. If we also take into account that I am holding that remote work should be interpreted as a capability rather than as a functioning, it becomes clear that I am only maintaining that workers should be given the chance to wean themselves from the office, even if this may cause suffering. Whether the individual chooses to take up this opportunity, should remain a private choice.

Much of what I said in response to point (a) could also be said with respect to points (b) and (c). It is surely possible that by working from home the worker will not be able to grasp the sense of the collective productive effort, for the simple reason that she/he will not see the place where others work, but can only imagine it (b). I think that this fear is less founded than the previous one (a), because digital meetings and exchanges, if well organized, can (at least partially) substitute for the live vision of the work of others. And we should also consider that also in traditional offices many workers tend to be isolated, for most of the day, from others (e.g., a social media manager of a large logistics company might never enter the warehouses). Nonetheless, even though my observations were wrong and point (b) were stronger than it seems to me, the loss of a collective sense of one's work could be compensated for by a newfound collective sense of the individual's role in society. 
In other words, a worker free from the spatial constraint of the office could rediscover the meaning of her/his existence in her/his neighbourhood, in her/his city, in her/his country, choosing freely the collective activities (cultural, political, social in the broadest sense of the term) to which she/he intends to devote herself/himself. That is, we must free ourselves from the idea that work is an irreplaceable source of meaning. If we are to respect the $\mathrm{HF}$, a valid alternative to making work more meaningful is to make non-work life more meaningful.

Lastly, it could be argued that many workers, especially those in a position of power, if physically separated from the office and colleagues, are forced to give up a number of relational and physical markers of identity. Relational markers of identity are all the gestures, attitudes and actions that identify the worker's position within the group: e.g., the way the worker addresses her/his colleagues, the deference and respect (or even lack of respect) that others show her/him, the things that the worker does for others and others do for her/ him. The physical markers of identity, instead, are the objects and spaces through which the worker shapes the image she/he wants to convey (or must convey) to others (Elsbach 2004). Imagine a manager who is used to arriving at the office on a motorbike, dressed in the latest fashion, and moving with ease in an office where she/he displays sports trophies and complicated economics books. In a remote working environment, it is difficult, if not impossible, for this manager to convey the more or less artificial image of herself/himself to her/his colleagues: that of a brilliant and sporty person, who knows how to win trophies, deal with company problems and also choose fashionable clothes.

Here the knot is much easier to untie, at least from a Kantian perspective. Forcing other people to do their work in one place because this is the only way to effectively convey the image one wants to give of oneself to one's colleagues, means treating other people as means, and this violates the HF. Moreover, as in the previous cases, the choice here is not between showing oneself and not doing it, bur rather between showing oneself inside or outside the office. Here, too, the fact that the worker does not find valid alternatives to the people to whom she/he wishes to convey a certain individual image is a symptom of a social pathology, the cannabalisation of the private sphere by the working sphere.

\section{Conclusions}

In this paper I moved from the premise that the Covid-19 pandemic dispelled a prejudice that existed with respect to remote work: that its economic advantages (lower variable and fixed costs for employers) were lower that its economic disadvantages (a loss in worker productivity and innovativeness). Many studies demonstrated that workers can be as much productive (and in many cases even more productive) as remote workers than as office workers. And obviously this is subject to further improvement through practice. This makes it essential to reconsider, from a normative point of view, whether the employee's obligation to go to the office is coercive or not.

I conducted this analysis through the Kantian notion of meaningful work, elaborated by Bowie on the basis of the humanity formulation of the categorical imperative: to treat oneself and others as ends rather than as means. I explained why the notion of meaningful work should be interpreted through the lens of the "bearable costs" clause. While work, understood as the application of one's abilities to transform the world around us, is in itself an activity that promotes the free exercise and development of one's rationality, wage labour is not necessarily so. Unless, however, one wants to make a broader critique of the 
very concept of capitalism (which I would leave aside here), the employment contract is indispensable for many, or at least for those who cannot live on their income or as freelancers. Thus, if wage labour is both indispensable and impeding with respect to individual autonomy and human development, the employer's duty to offer meaningful work to the worker finds a limit only at the point where a marginal increase in meaningfulness for the worker represents an economic risk for the employer. There is therefore a margin of loss of profit, which precedes the economic risk for the company, and which is compatible with the imperfect moral duty to offer remote work to employees.

The second part of the article was devoted to the argument that, for many jobs, remote work falls under the "bearable costs" clause. I addressed the innovation objection, which holds that remote workers tend on average to be less innovative (mainly as team members) when working remotely than in an office. I argued that the objection is less strong than many believe, and the Covid-19 experience has proved it. I also explained why even in those cases where the innovation objection is successful (i.e. where it shows that taking into account all other factors, remote working causes a loss of innovativeness which in turn translates into a loss of profit for the company), as long as the loss of profit does not turn into an economic risk for the survival of the company, the moral argument in favour of the moral autonomy promoted by remote work is superior to any argument in favour of profit maximization. Moreover, I tend to believe that, in the medium run, remote work could unleash new sources of inspiration and innovation in individuals, which will eventually compensate for the economic value of any problems in the group dynamics of remote working.

Lastly, I dealt with the isolation objection, which is based on the empirical findings that many workers felt bad working from home during the Covid-19 pandemic. I maintained that far from being an argument against remote working, this is a demonstration of how unmeaningful the work of those who are forced to work in an office is, if they cannot find viable social alternatives to those imposed on them by their employer.

\section{Declarations}

Conflict of Interest The author states that there is no conflict of interest.

\section{References}

Adecco. 2021. Attracting talent in the New World of remote working. 27 April. https://www.adeccogroup. com/future-of-work/latest-insights/attracting-talent-in-the-new-world-of-remote-working/

Bowie, N.E. 1999. Business ethics: A Kantian perspective. Hoboken, NJ: Blackwell Publishers.

Bowie, N. E. 2017. Business ethics: A Kantian perspective, Second Edition. Cambridge: Cambridge University Press.

Capgemini. 2020. The Future of work: From Remote to Hybrid. https://www.capgemini.com/it-it/wp-conte nt/uploads/sites/13/2021/03/The-Future-of-Work_Final.pdf

Ciulla, J.B. 2012. Worthy work and Bowie's Kantian theory of meaningful work. In Kantian business ethics: Critical perspectives, ed. D.G. Arnold and J.D. Harris, 115-131. Cheltenham, UK: Edward Elgar Publishing.

DesJardins, J.R. 2012. Meaningful work. In Kantian business ethics: Critical perspectives, ed. D.G. Arnold and J.D. Harris, 132-147. Cheltenham, UK: Edward Elgar Publishing.

Duell A. 2021. Truth \& Alienation in a Covid world. Philosophy Now 143. https://philosophynow.org/ issues/143/Truth_and_Alienation_In_a_Covid_World 
Engelbrecht, H.J. 2014. A general model of the innovation - subjective well-being nexus. Journal of Evolutionary Economics 24: 377-397. https://doi.org/10.1007/s00191-014-0343-y.

Eurofond. 2021. Living, working and COVID-19. COVID-19 series. Luxembourg: Publications Office of the European Union. https://www.eurofound.europa.eu/sites/default/files/ef_publication/field_ef_ document/ef20059en.pdf

FlexJobs. 2020. Productivity, work-life balance improves during pandemic. September 21. https://www.flexj obs.com/blog/post/survey-productivity-balance-improve-during-pandemic-remote-work/

Formosa, P. 2014. Dignity and respect: How to apply Kant's formula of humanity. The Philosophical Forum 45: 49-68. https://doi.org/10.1111/phil.12026.

Gini, A. 1998. Work, identity and self: How we are formed by the work we do. Journal of Business Ethics 17: 707-714. https://doi.org/10.1023/A:1017967009252.

Herman, B. 2010. Being helped and being grateful: Imperfect duties, the ethics of possession, and the Unity of morality. The Journal of Philosophy 109: 391-411. https://doi.org/10.5840/jphil20121095/616.

Hickman A. 2019. Workplace isolation occurring in remote workers. Dissertation, Walden University. https://scholarworks. waldenu.edu/cgi/viewcontent.cgi?article $=8181 \&$ context $=$ dissertations

Hill, T.E., Jr. 1980. Humanity as an end in itself. Ethics 91: 84-99.

Hill, T.E., Jr. 2002. Human welfare and moral worth: Kantian perspectives. Oxford: Oxford University Press.

Hope, S. 2014. Kantian imperfect duties \& human rights. The Journal of Political Philosophy 22: 396-415. https://doi.org/10.1111/jopp.12026.

Kant, I. 1785. Groundwork of the metaphysics of morals. Trans. M. Gregor. Cambridge: Cambridge University Press, 1998.

Kant, I. 1795. Toward perpetual peace: A philosophical sketch. In Toward perpetual peace and other writings on politics, peace, and history, ed. P. Kleingeld. New Haven: Yale University Press, 2006.

Kelly J. 2020. Digital nomad: The new and cool trend of working from paradise-Or anywhere in the world. Forbes, September 8. https://www.forbes.com/sites/jackkelly/2020/09/08/digital-nomad-the-new-andcool-trend-of-working-from-paradise-or-anywhere-in-the-world/?sh=516243704246

Keynes J.M. 2008. Economic possibilities for our grandchildren. In Revisiting Keynes economic possibilities for our grandchildren, ed. L. Pecchi and G. Piga G., 17-26. Cambridge MA: MIT Press, 1930.

Kleingeld, P. 1999. Kant, history, and the idea of moral development. History of Philosophy Quarterly 16: 59-80.

McKinsey 2020. What's next for remote work: An analysis of 2,000 tasks, 800 jobs, and nine countries. November 23. https://www.mckinsey.com/featured-insights/future-of-work/whats-next-for-remotework-an-analysis-of-2000-tasks-800-jobs-and-nine-countries\#.

Microsoft 2021. The next great disruption is hybrid work - Are we ready?. March 22. https://ms-worklab. azureedge.net/files/reports/hybridWork/pdf/2021_Microsoft_WTI_Report_March.pdf

Morgan K. 2020. Why your in-office friendships still matter. BBC, September 30. https://www.bbc.com/ worklife/article/20200925-why-your-in-office-friendships-still-matter

Nelson, W. 2008. Kant's formula of humanity. Mind 17: 85-106. https://doi.org/10.1093/mind/fzn004.

O’Neill, O. 2000. Bounds of justice. Cambridge: Cambridge University Press.

PwC. 2021. US remote work survey. January 12. https://www.pwc.com/us/en/library/covid-19/us-remotework-survey.html

Russell B. 2004. In praise of idleness - And other essays, 2nd edition. London \& New York Routledge, 1935 .

Samuels, A. 2020. The coronavirus is making us see that It's hard to make remote work actually work. Time (March 13) https://time.com/5801882/coronavirus-spatial-remote-work/.

The Economist. 2021. Special report: The future of work, April 10.

Whitney, L. 2021. How remote working still poses security risks for organizations. TechRepublic, March 23. https://www.techrepublic.com/article/how-remote-working-still-poses-security-risks-for-organizations/

Publisher's Note Springer Nature remains neutral with regard to jurisdictional claims in published maps and institutional affiliations. 